\title{
INCLUSIVE FUNDING FOR ENHANCED IMPACT OF SOCIAL SCIENCES AND HUMANITIES
}

\author{
MALIN LINDBERG, SVETLANA GROSS, MILDA RÖNN, LISSA NORDIN, JAN SANDRED, LARS WÄRNGÅRD AND \\ CATHARINA NORBERG
}

DOI: 10.22163/fteval.2019.372

\section{ABSTRACT}

I n order to expand the knowledge on how societal impact of social sciences and humanities (SSH) can be enhanced through public funding of research and innovation, a process of designing digitalised tools for inclusive funding is scrutinised, involving four Swedish funding agencies and an Non-Governmental Organisation (NGO) of SSH researchers. The agencies shared the challenge to attract a broader range of SSH researchers to apply for their funding. Excluding and including mechanisms were identified in the interactions, texts and images of the formulation, communication and processing of calls for funding. The developed tools digitally guide the user through queries regarding the present and potential diversity of SSH representation among applicants, reviewers, agency staff, etc. and regarding the formulation and communication of call texts, assessment criteria and reviewer instructions. The tools thus enhance SSH impact by making funding more available, but fail to demonstrate how concrete interaction with societal actors may enhance this.

\section{INTRODUCTION}

Despite the widely acknowledged importance of social sciences and humanities (SSH) for understanding and enhancing societal development, public support structures for knowledge transfer, innovation and impact of research in society have traditionally focused natural sciences, engineering and technology (SET) (Brundenius et al., 2016; Olmos Peñuela et al, 2014; Wutti and Hayden, 2017). This is part of a more encompassing pattern, where also policy and research on innovation and growth have focused industrial, technological and commercial renewal rather than social transformation (cf. Dawson and Daniel, 2010; Godin, 2014; Lindberg, 2012, 2018; van der Have and Rubalcaba, 2016). The importance of SSH research for innovation and impact is however increasingly emphasised in EU policy strategies on "Science with and for Society" (SwafS), "Responsible Research and Innovation" (RRI), "Open Science", etc. (European Union, 2014, 2016, 2017). This is accompanied by a rapidly increasing academic interest in social innovation, with reference to new figurations or combinations of social practices that meet social needs, where SSH knowledge is esteemed as pivotal (Brandsen et al., 2016; Brundenius et al., 2016; Howaldt et al., 2018; Moulaert et al., 2013; Nicholls et al., 2015).
As a consequence of this trend in policy and research, public funding agencies are expected to improve their support of SSH impact. In Sweden, four national funding agencies joined forces with a national NGO of SSH researchers in the design of a set of digital tools for inclusive funding of research and innovation (R\&I). The process that took place 2014-2018, is in this paper used as a springboard for expanding the knowledge on how public Ryl funding may be designed in order to enhance SSH impact. The main research question concerns what excluding and including mechanisms towards SSH researchers that were delineated in the process, and how these mechanisms impacted the design of digital tools for inclusive funding. Previous studies on academic impact support serve to theoretically contextualise these mechanisms and tools. A participatory research approach, where new knowledge is developed jointly by researchers and other societal actors, serves to ensure the social contextualisation of the process and results.

Initially, the theoretical framework of academic impact support is presented. This is followed by an outline of the participatory research design. Subsequently, the results are presented in terms of identified mechanisms of inclusion and exclusion, and their impact on the tool design. Finally, conclusions are drawn regarding how digital tools for inclusive funding may be designed in a way that enhances SSH impact.

\section{IMPACT SUPPORT}

In Sweden and several other European countries, public support services for knowledge transfer, innovation and impact are offered by Ryl funding agencies, university innovation offices, technology transfer offices, academic incubators, science parks, etc. These institutions generally provide financial and/or non-financial support in terms of grants, loans, investments, business counselling, peer-to-peer support, networks, testbeds, training, lectures, etc. As most of these support services traditionally target researchers and innovators in technology, engineering and natural sciences, needs within social sciences and humanities are insufficiently met (cf. Bakhshi et al., 2008; Brundenius et al., 2016; Dawson and Daniel, 2010; Howaldt et al., 2018; Lindberg, 2012, 2018; Lindberg and Nahnfeldt, 2013; Lundström and Zhou, 2011; Muhonen et al., 2018; Olmos Peñuela et al., 2014; Phipps et al., 2012; TEPSIE, 2012, 2014; Wutti and Hayden, 2017). Studies have identified both environmental barriers - e.g. lack of support structures in terms of funding, counselling, 
networks, etc. - and actor-related barriers - e.g. lack of capacities and competencies - for realising and growing innovations with prominent social motives and components (Brandsen et al., 2016; Howaldt et al., 2018; TEPSIE, 2012, 2014). This reflects the "reasonably settled consensus within the innovation community that science, engineering and technology (STEM) research is more 'useful' to societies than other types of research, notably social sciences and humanities (SSH) research", noted by Olmos Peñuela et al. (2014:384). The further note that by seeking to "increase and concentrate (RqI) funding on areas that bring the greatest, narrowly economic return", governments tend to regard SSH research as "not worthy of investment" (ibid:385).

SSH do however matter in societal progress, "because they help us understand and address wicked problems (...) about which there is little agreement on solutions", according to Phipps et al. (2012:167). It is advocated that SSH provide insights into - and innovative solutions to - current societal challenges of poverty, immigration, climate change, security, health, etc. (Bakhshi et al., 2008; Lindberg and Nahnfeldt, 2013; Phipps et al., 2012; Wutti and Hayden, 2017). Traditional impact indicators of patents, licenses and spin-off companies are thus too narrow for estimating SSH impact (Lundström and Zhou, 2011; Muhonen et al., 2018; Olmos Peñuela et al., 2014; Wutti and Hayden, 2017). SSH have a well-documented tradition of engagement practices towards users, thus producing results that these users value, but that may be difficult to measure in terms of macro-economic impact (Olmos Peñuela et al., 2014). A study of 1600 Spanish researchers exposes that SSH achieve its impact not primarily by direct interaction with businesses, but by indirect interaction through creating content for the media, and by cooperating more directly with government and civil society organisations to improve the quality of life (ibid). An Austrian study similarly detects SSH impact in terms of transmission of academic knowledge into professional practice and public spheres, not primarily seeking to obtain profits, but rather raising consciousness (Wutti and Hayden, 2017). Based on a comparative analysis of 60 examples from 16 European countries, Muhonen et al. (2018) proposes a framework for estimating impact that considers both societal interaction and the societal changes it enhances. These examples highlight SSH impact through "social innovation", i.e. the development of new figurations or combinations of social practices that meet social needs (Brandsen et al., 2016; Grimm et al., 2013; Howaldt et al., 2018; Moulaert et al., 2013; Nicholls et al., 2015; Phipps et al., 2012).

The public and academic interest in social innovation has rapidly grown during the last decade, as a way to handle complex societal challenges (Brandsen et al., 2016; Grimm et al., 2013; Howaldt et al., 2018; Moulaert et al., 2013; Nicholls et al., 2015). This has served to consolidate social innovation studies as a multi-disciplinary research field, providing insights into the development of new solutions for improved welfare, wellbeing and relations among various groups and communities, especially those perceived as economically or socially vulnerable (Cajaiba-Santana, 2013; Dawson and Daniel, 2010; Haxeltine et al., 2017; Ionescu, 2015; Pol and Ville, 2009; van der Have and Rubalcaba, 2016). According to several studies, social innovation is characterised by active involvement of those groups that are to benefit from the developed solutions, making individual and collective empowerment a crucial component of such processes (Brandsen et al., 2016; Howaldt et al., 2018; Moulaert et al., 2013; Nicholls et al., 2015). These studies also characterise social innovation processes as complex multi-actor and multi-level endeavours, where public, private and civil sector actors on various organisational and geographical level are forced to interact, in order to pro- perly understand and address complex social systems. Transformation of these systems are dependent upon the interplay between structure and agency, i.e. established institutions, regulations and norms, on the one hand, and individual's capacity to challenge or enforce these structures, on the other hand (Haxeltine et al., 2017; Westley et al., 2017). The complex nature of social innovations and the challenges they address, makes SSH expertise on human relations, social progress and organisational development pivotal in such processes (Brundenius et al., 2016; Grimm et al., 2013; Lundström and Zhou, 2011; Phipps et al., 2012).

A global mapping of over 1000 social innovations expose, however, that researchers and other university officials are involved only in 15 percent of the mapped cases (Butzin and Terstriep, 2018). In contrast, public authorities, civil society organisations and private companies are more frequently involved, amounting to about 40 percent of the cases. This contrasts to the prominent role of universities and researchers in traditional innovation processes, focusing technological and industrial innovation. In social innovation, researchers tend to be replaced as knowledge providers by users, beneficiaries and consultants, in line with the grassroot character of such processes (Butzin and Terstriep, 2018; Domanski and Kaletka, 2018; Sørensen and Torfing, 2015). As noted by Phipps et al. (2012:167-168), "new SSH knowledge that isn't shared cannot contribute to (...) social innovations", calling for improved "knowledge mobilization" to maximise societal impact of SSH, through the use of knowledge brokers and social media. It is predicted that universities will be increasingly inclined to invest in knowledge transfer services to support SSH in the co-production of societally useful knowledge (Lindberg and Nahnfeldt, 2013; Lundström and Zhou, 2011; Phipps et al., 2012). Lundström and Zhou (2011) note the establishment of 'social innovation parks' in various parts of the world, where SSH knowledge either forms the basis for or enriches development of new solutions to societal challenges. Lindberg and Nahnfeldt (2013) discern that public support services could enhance SSH innovation through improved competences regarding how to design, finance and scale social solutions, through revised procedures and tools to fit the needs and prerequisites among SSH researchers/innovators, as well as through alternative words and images - e.g. by referring to "ideas" rather than "innovations" and images of people instead of machinery - to illustrate and inspire academic innovation. Bakhshi et al. (2008) conclude that national funding agencies may enhance wider contributions of SSH to innovation by setting SSH-suitable standards for evaluating good practices of knowledge transfer, by supporting team-based collaboration across disciplines, by facilitating a culture of knowledge transfer with societal actors, and by functioning as active knowledge brokers through face-to-face networking, personal contacts, representation on external boards, panels and steering groups, etc. The role of national funding agencies as knowledge brokers is further scrutinised by de Jong et al. (2016), exposing that despite their efforts to apply impact criteria in their funding, in line with government policies, it remains unclear to many researchers how impact should be organised, presented and assessed.

\section{RESEARCH DESIGN}

In order to expand the knowledge on how public Rgl funding may be designed in order to enhance SSH impact, the study employs a participatory research approach, where new knowledge is developed jointly by researchers and other societal actors (Aagaard Nielsen and Svensson, 
2006; Reason and Bradbury, 2008). The researchers represented a Swedish NGO of SSH researchers (Humsamverkan) that joined forces with representatives from four national R\&l funding agencies (Formas - The Swedish Research Council for Sustainable Development, Forte - The Swedish Research Council for Health, Working life and Welfare, Energimyndigheten - The Swedish Energy Agency, VINNOVA - Sweden's Innovation Agency) - in a process of designing digital tools for inclusive funding of research and innovation. Two researchers from Humsamverkan facilitated the process, while the agency representatives contributed with their practical experiences. During 2014-2018, they incrementally delineated excluding and including mechanisms towards SSH researchers in their processes of formulating, communicating and processing calls for funding. This took place at regular workshops, alternately arranged individually with each agency and collectively with all agencies. Based on the acquired insights, tools were piecewise collectively designed during continued, joint workshops. The tools were publicly launched in the spring of 2018, freely available at www.humsamverkan.se (in Swedish only).

In order to simultaneously expand the academic knowledge on how public Ryl funding may be designed to enhance SSH impact, the participating researchers and agency representatives decided to scientifically analyse the process and results, in line with the participatory research approach of joint knowledge development (cf. Aagaard Nielsen and Svensson, 2006; Reason and Bradbury, 2008). The results of that analysis form the basis for this paper that is co-authored by the main participants. The participatory procedure helps attaining 'socially robust knowledge', as the results are validated through continuous dialogue between those who possess practical experiences and academic knowledge in the studied area (Nowotny et al., 2001). The data informing the study consists of meeting minutes, tool drafts and the finalised tools, collected at the workshops during 2014-2018. The collected data was then analysed in the light of the theoretical framework of academic impact support, as part of the joint writing process. As part of this, a thematic analysis was performed in order to distinguish excluding and including mechanisms towards SSH researchers (cf. Guest et al., 2012).

\section{RESULTS}

Motivated by the rising interest in European policy and research for SSH impact and innovation, the four national funding agencies joined forces with the national NGO of SSH researchers in 2014, in order to delineate excluding and including mechanisms towards SSH researchers in their calls for funding, as a basis for designing digital tools for inclusive RYl funding, which were launched in 2018 (available in Swedish at www.humsamverkan.se). The agencies shared the ambition to promote societal progress through their funding, as well as the challenge to attract a broader range of SSH researchers to apply for their funding. In order to improve their understanding of obstacles and opportunities for inclusive funding, they started off by identifying excluding and including mechanisms towards SSH researchers in their processes of formulating, communicating and processing calls for funding. Firstly, they delineated their call processes, identifying each phase from initial initiative till final funding decisions. Even if each agency had their own, specific routes for initiating and managing calls, common phases included identification of relevant areas or challenges to address in the call, formation of a staff team to manage the call, formulation of the call text, communicating of the call to target groups, reviewing applications and communicating decisions.

In each of the delineated phases, crucial interactions between staff, target groups, intermediaries and other stakeholders were pinpointed. Key texts and images were also identified, including instructions from government and top management, call texts, websites, other marketing material, evaluation instructions, decision letters, etc. The delineated interactions, texts and images were then scrutinised with regard to their potentially excluding or including effects on SSH researchers from various disciplines. In the interactions, such mechanisms were primarily identified in the composition of the staff team, the contact networks with intermediaries for communicating the call, the presentation forms for communicating the call, as well as the composition of - and instructions to - review committees. Excluding or including effects were perceived to be dependent on the representation and application of a variety of competence areas in these interactions, including a variety of SSH-specific ones. In the texts, similar mechanisms were identified primarily in the description of the addressed areas or challenges, in the demanded competence profile, in the assessment criteria, as well as in the headings and structure of power point presentations. Excluding or including effects were perceived to be dependent on the choice and ordering of specific terms and criteria, intentionally or unintentionally linked to specific research disciplines or ideological/political norms. Such links could either be explicit or implicit, concrete or abstract, specific or generic. Both explicitly and implicitly stated disciplines - named directly or implicated through discipline-specific terminology - might give the impression that only researchers in these disciplines are the target group for the call. The order in which certain areas or criteria are presented might also affect who is appealed by the call, where areas/criteria that are presented first often are perceived as the most important. If the most limiting areas/ criteria are presented first, a narrower range of applicants will probably be appealed, than if it is presented last. In the images, excluding and including mechanisms were identified primarily in the illustrations in call texts, websites and power point presentations. The effects were perceived to be dependent on the representation of a variety of researchers, disciplines, areas, etc., in a variety of formats and settings.

The delineation of these excluding and including mechanisms was used as a springboard for designing a set of digital tools for inclusive Ryl funding. The ambition was that the tools would be useful both for the participating agencies, as well as other funding agencies in Sweden, in the strive for improved societal impact through broadened representation of researchers and disciplines. Besides improved SSH representation, the tools might serve to enhance applications from other under-represented groups as well, in regard to gender, origin, age, etc. The designed tools encompass three main entry points: 1) What do we miss out?, 2) What are the reasons? 3) What can we do?. When entering any of these, the user is guided through a set of awareness-raising and practice-oriented queries. Three to four main queries accompany each point, further specified in a number of sub-queries. The user is encouraged to use a previous or potential call for funding as a basis, when responding to the queries. The first entry point - What do we miss out? - is followed by three main queries: 1) Who has applied and been granted funding - and who has not?, 2) What kind of applicants and granted applications would have been desirable, 3) How can the insights into what applicants have been missed out be improved?. Examples of sub-queries are: How well are various disciplines represented among applicants and granted applications?, Are the approval-rates the same for various disciplines?, What 
disciplines ought to be represented in order to properly understand the addressed area?. To enhance the reflections, a list of all existing SSHdisciplines is provided.

The second entry point - What are the reasons? - is followed by four main queries: 1) How is the call text formulated?, 2) What criteria are applied in the call?, 3) How is the call communicated?, 4) How are the applications reviewed?. Examples of sub-queries are: To what extent is a broad variety of disciplines represented among staff, reviewers, applicants, intermediaries and other stakeholders?, What explicit, implicit or absent disciplines are distinguishable in the texts and images of the call, and to what extent do these reflect a broad variety of disciplines?, To what extent do existing criteria qualify or disqualify applicants from a broad variety of disciplines?, Do the established communication channels reach a wide variety of researchers?. The third entry point - What can we do? - is followed by three main queries: 1) Do we need more knowledge?, 2) Do we need to change our routines and frameworks?, 3) Do we need to develop internal routines and support functions?. Examples of sub-queries are: What new knowledge is needed in order to understand and counteract the excluding mechanisms identified in the first and second entry point?, What new instructions, courses, forms or other routines and support functions can be established in order to attain a greater variety of applicants and granted applications?, Who possesses the organisational power to alter comprehensive frameworks or regulations?.

The entry points are complemented by three fictional case-examples, of which one is presented below.

\section{A CALL THAT DOES NOT REACH ITS INTENDED TARGET GROUPS}

A call for funding of research about sustainable transport systems intends to engender new knowledge on how traffic volumes may be reduced by infrastructural planning. The agency esteem that comprehensive studies are needed, spanning from how actors communicate during planning processes to how norms and discourses affect their decisions. The agency therefore wants to attract a variety of applicants to the call, not least from social sciences and humanities.

The call is however formulated in a way that assumes that the reader already possesses expertise in the transport area. It contains, for example, several expressions that are specific to the area. The text thus signals that the call is directed to a specific, narrow group of transport experts. When communicating the call through newsletters and information meetings, the agency makes no attempt to explain the area-specific expressions to a wider audience.

As a result, the financier does not attain the aspired variety of applicants. The few applications received only come from researchers who are already accustomed to applying for funding from transport-specific calls.

\section{CONCLUSIONS}

The joint design of digital tools for inclusive R\&l funding, as depicted in the preceding section, serves to expand the knowledge on how such efforts may enhance SSH impact. Similar to the argumentation in previous studies on academic impact support, the process was motivated by the acknowledged ability of SSH to provide insights into and innovative solutions to complex societal challenges (cf. Bakhshi et al., 2008; Brundenius et al., 2016; Grimm et al., 2013; Lindberg and Nahnfeldt, 2013; Lundström and Zhou, 2011; Phipps et al., 2012; Wutti and Hayden, 2017). In line with previously identified barriers to SSH impact and innovation, the participating funding agencies and SSH researchers perceived the narrow range of SSH disciplines represented among applicants as hampering to such ambitions (cf. Brandsen et al., 2016; Howaldt et al., 2018; TEPSIE, 2012, 2014). The joint ambition was to address both environmental barriers in terms of granted funding and actor-related barriers in terms of improved capacities and competencies to provide such funding (cf. ibid). The process thus acknowledged that transformation of complex social systems requires an interplay between established institutions, regulations and norms, on the one hand, and individuals' capacity to challenge and change such structures, as concluded in previous studies (cf. Haxeltine et al., 2017; Westley et al., 2017).

The first research question, regarding what excluding and including mechanisms towards SSH researchers that are delineated in the process, exposes that such mechanisms are at play through all phases of the call processes, including identification of areas to address, staff team formation, call text formulation, target group communication, application review and decision communication. The interactions, texts and images in each phase are delineated as especially relevant. In the light of SET-related norms of economic and commercial impact, pinpointed in previous studies on academic impact support, the delineated mechanisms mainly concern: 1) the variety of SSH-related competences represented among the agency staff and review committees, 2) the presence of SSH-tailored area descriptions, terms and assessment criteria, in call texts, website information, power point presentations, reviewer instructions, etc. (cf. Bakhshi et al., 2008; Brundenius et al., 2016; Dawson and Daniel, 2010; Howaldt et al., 2018; Lindberg, 2012, 2018; Lindberg and Nahnfeldt, 2013; Lundström and Zhou, 2011; Muhonen et al., 2018; Olmos Peñuela et al., 2014; Phipps et al., 2012; TEPSIE, 2012, 2014; Wutti and Hayden, 2017). The identified excluding mechanisms enforce - just as the including mechanisms challenge - the perception of SET being more useful and investment-worthy for the society (cf. OImos Peñuela et al., 2014).

The second research question, regarding how the identified mechanisms impacted the design of digital tools for inclusive funding, exposes that three main entry points - regarding what is missed out, why this is missed, and what can be changed - were perceived as the most crucial. By guiding the user through queries regarding the present and potential diversity of SSH representation among applicants, granted applications, reviewers, intermediaries, contact networks and agency staff, a pathway to more inclusive funding is established. The path is further clarified by queries regarding the formulation and communication of call texts, assessment criteria and reviewer instructions, as well as organisational routines and support for enhanced SSH impact. The tool design thus concords with conclusions in previous studies, regarding the crucial function of public funding agencies as knowledge brokers, by encouraging 
societal knowledge transfer in general, and tailored tools and criteria, widened communication paths, alternative words and images, etc. in particular (cf. Bakhshi et al., 2008; de Jong et al., 2016; Lindberg and Nahnfeldt, 2013)

By underlining the need for simultaneous changes of practical call design and strategic organisational frameworks, the developed tools reflect the crucial interplay between established procedures/norms and individual/collective empowerment (cf. Haxeltine et al., 2017; Westley et al., 2017). When attempting to make the funding more inclusive towards underrepresented groups, conflicts may arise in relation both to other missions and tasks of the agencies, and to conservative attitudes among agency managers, staff and other stakeholders. A similarly hampering factor is that neither the identified mechanisms nor the designed tools consider how SSH impact may be enhanced through concrete interaction with users and other stakeholders from various societal sectors, highlighted as pivotal in previous studies (cf. Brandsen et al., 2016; Howaldt et al., 2018; de Jong et al., 2016; Moulaert et al., 2013; Muhonen et al., 2018; Nicholls et al., 2015; Olmos Peñuela et al., 2014; Wutti and Hayden, 2017). As social innovation studies underline the importance of active involvement of users and stakeholders in order to enable both individual and collective empowerment, the intended enhancement of SSH impact may have been hampered (cf. Brandsen et al., 2016; Howaldt et al., 2018; Moulaert et al., 2013; Nicholls et al., 2015). This is especially concerning, as researchers tend to be replaced as knowledge providers by users, beneficiaries and consultants in social innovation processes, thus missing out on valuable SSH expertise on human relations, social progress and organisational development (cf. Brundenius et al., 2016; Butzin and Terstriep, 2018; Domanski and Kaletka, 2018; Grimm et al., 2013; Lundström and Zhou, 2011; Phipps et al., 2012; Sørensen and Torfing, 2015).

\section{REFERENCES}

Aagaard Nielsen, K. and Svensson, L. (Eds.) (2006). Action research and participatory research. Maastricht: Shaker Publishing.

Bakhshi, H., Schneider, P. and Walker, C. (2008). Arts and Humanities Research and Innovation. London/Bristol: NESTA and Arts and Humanities Research Council.

Brandsen, T., Cattacin, S., Evers, A. and Zimmer, A. (Eds.) (2016). Social innovations in the urban context. New York: Springer.

Brundenius, C., Göransson, B. and Carvalho de Mello, J. M. (Eds.) (2016). Universities, Inclusive Development and Social Innovation: an international perspective. Cham: Springer.

Butzin, A. and Terstriep, J. (2018). Actors and Roles in Social Innovation. In J. Howaldt, C. Kaletka, A. Schröder and M. Zirngiebl (Eds). Atlas of Social Innovation - New Practices for a Better Future. Dortmund: Sozialforschungsstelle, TU Dortmund University.

Cajaiba-Santana, G. (2013). Social innovation: Moving the field forward. A conceptual framework. Technological Forecasting \& Social Change. 82(1): 42-51.
Dawson, P. and Daniel, L. (2010). Understanding social innovation: a provisional framework. International Journal of Technology Management. 51(1): 9-21.

de Jong, S. P. L., Smit, J., van Drooge, L. (2016). Scientists' response to societal impact policies: A policy paradox. Science and Public Policy. 43(1):102-114.

Domanski, D. and Kaletka, C. (2018). Social Innovation Ecosystems. In J. Howaldt, C. Kaletka, A. Schröder and M. Zirngiebl (Eds). Atlas of Social Innovation - New Practices for a Better Future. Dortmund: Sozialforschungsstelle, TU Dortmund University.

European Union (2017). $\angle A B$ - FAB - APP - Investing in the European future we want. Report of the independent High Level Group on maximising the impact of EU Research \& Innovation Programmes. Brussels: European Commission.

European Union (2016). Open Innovation, Open Science, Open to the World. Brussels: European Commission.

European Union (2014). Science with and for Society. HORIZON 2020 Work Programme 2014-2015. Brussels: European Commission.

Godin, B. (2014). An old word for a new world, or the de-contestation of a political and contested concept. In K-E. Sveiby, P. Gripenberg and B. Segercrantz (Eds.). Challenging the Innovation Paradigm. New York/ London: Taylor and Francis.

Grimm, R., Fox, C., Baines, S. and Albertson, K. (2013). Social innovation, an answer to contemporary societal challenges? Innovation: The European Journal of Social Sciences. 26(4): 436-455.

Guest, G., MacQueen, K. M. and E. E. Namey (2012). Applied thematic analysis. Thousand Oaks: SAGE.

Haxeltine, A., Pel, B., Dumitru, A., Avelino, F., Kemp, R., Bauler, T., Kunze, I., Dorland, J., Wittmayer, J. and Jørgensen, M. S. (2017). Towards a TSI theory: a relational framework and 12 propositions. TRANSIT.

Howaldt, J., Kaletka, C., Schröder, A. and Zirngiebl, M. (2018). Atlas of Social Innovation - New Practices for a Better Future. Dortmund: Sozialforschungsstelle, TU Dortmund University.

Ionescu, C. (2015). About the conceptualization of social innovation. Theoretical \& Applied Economics, Vol. 22 No. 3, pp.53 - 62.

Lindberg, M. (2012). A striking pattern - Co-construction of innovation, men and masculinity in Sweden's innovation policy. In S. Andersson, K. Berglund, J. Thorslund, E. Gunnarsson and E. Sundin (Eds.). Promoting Innovation. Stockholm: VINNOVA, pp. 47-67.

Lindberg, M. (2018). Relating inclusiveness and innovativeness in inclusive innovation. International Journal of Innovation and Regional Development. 8(2): 103-119. 
Lindberg, M. and Nahnfeldt, C. (2013). Commercializing work life balance - outlining a model for analyzing and promoting social science innovation. International Journal of Innovation Science. 5(1): 21-30.

Lundström, A. and Zhou, C. (2011). Promoting innovation based on social sciences and technologies: the prospect of a social innovation park. Innovation - The European Journal of Social Science Research. 24(1-2): 133-149.

Moulaert, F., MacCallum, D., Mehmood, A. and Hamdouch, A. (Eds.) (2013). The international handbook on social innovation. Cheltenham: Edward Elgar.

Muhonen, R., Benneworth, P. S. and Olmos Peñuela, J. (2018). From productive interactions to impact pathways: Understanding the key dimensions in developing SSH research societal impact. CHEPS working paper; Vol. 2018, No. 02. Center for Higher Education Policy Studies (CHEPS).

Nicholls, A., Simon, J. and Gabriel, M. (Eds.) (2015). New Frontiers in Social Innovation Research. New York: Palgrave Macmillan.

Nowotny, H., Scott, P. and Gibbons, M. (2001). Re-thinking science - knowledge and the public in an age of uncertainty. Cambridge: Polity Press.

Olmos-Penuela, J., Benneworth, P., Castro-Martinez, E. (2014). Are STEM from Mars and SSH from Venus? Challenging disciplinary stereotypes of research's social value. Science and Public Policy. 41: 384-400.

Phipps, D. J., Jensen, K. E. and Myers, J. G. (2012). Applying Social Sciences Research for Public Benefit Using Knowledge Mobilization and Social Media. In A. Lopez-Varela Azcárate (Ed.). Theoretical and Methodological Approaches to Social Sciences and Knowledge Management. London: Intech0pen.

Pol, E. and Ville, S. (2009). Social innovation: Buzz word or enduring term?. The Journal of Socio-Economics. 38(6): 878-885.

Reason, P. and Bradbury, H. (Eds.) (2008). The Sage Handbook of Action Research. Participatory Inquiry and Practice. London: SAGE Publications.

Sørensen, E. and Torfing, J. (2015). Enhancing Public Innovation through Collaboration, Leadership and New Public Governance. In A. Nicholls, J. Simon, M. Gabriel (Eds.). New Frontiers in Social Innovation Research. New York: Palgrave Macmillan.

TEPSIE (2012). Barriers to social innovation. Brussels: European Commission.

TEPSIE (2014). Social Innovation Theory and Research - A Guide for Researchers. Brussels: European Commission.

van der Have, R. P. and Rubalcaba, L. (2016). Social innovation research: An emerging area of innovation studies? Research Policy. 45: 1923-1935.
Westley, F., McGowan, K. and Tjörnbo, 0. (Eds.) (2017). The evolution of social innovation: building resilience through transitions. Cheltenham: Edward Elgar Publishing.

Wutti, D. and Hayden, M. (2017). Knowledge Transfer in the Social Sciences and Humanities (SSH) - Definition, Motivators, Obstacles, and Visions. Colloquium: New Philologies. 2(1): 87-101.

\section{AUTHORS}

\section{MALIN LINDBERG}

Professor, Industrial Design, Luleå University of Technology

Luleå, 97187 (Sweden)

E: malin.lindberg@|tu.se

\section{SVETLANA GROSS}

PhD student, Stockholm School of Economics and Humsamverkan Stockholm, 11383 (Sweden)

\section{MILDA RÖNN}

Chair, Humsamverkan

Stockholm (Sweden)

\section{LISSA NORDIN}

Senior Analyst, Formas - Swedish Research Council for Sustainable Development

Stockholm, 11182 (Sweden)

\section{JAN SANDRED}

Project Officer, VINNOVA - Sweden's Innovation Agency

Stockholm, 10158 (Sweden)

\section{LARS WÄRNGÅRD}

Senior Advisor, Forte - Swedish Research Council for Health, Working life and Welfare

Stockholm, 10137 (Sweden)

\section{CATHARINA NORBERG}

Research Officer, Energimyndigheten - The Swedish Energy Agency Eskilstuna, 63104 (Sweden)

\section{KEYWORDS}

funding; humanities; impact; innovation; knowledge transfer, social sciences 